\title{
STRATEGI MANAJEMEN DALAM MENINGKATKAN DAYA SAING PADA CELEBRITY FITNESS CENTRAL PARK MALL
}

\author{
Christian Lyonal Wiseno \\ Program Studi Magister Manajemen Universitas Tarumanagara \\ christian.lyonal@gmail.com
}

\begin{abstract}
This research was conducted to find out the most precise management strategy to enhance competitiveness of Celebrity Fitness Central Park Mall. This study applies a qualitative method, by conducting interviews and also observation by directly reviewing the subject of the study. The analytical method consists Input Stage consisting of Internal Factor Evaluation and External Factor Evaluation, Matching Stage consisting of Strength-WeaknessOpportunity-Threat Matrix and Internal External Matrix, and Decision Stage consisting of Quantitative Strategic Planning Matrix. After analyzing from the existing data, it is known that the Market Penetration strategy is the most appropriate to be implemented for Celebrity Fitness Central Park Mall and Market Development strategy can be used as a support.
\end{abstract}

Abstrak : Penelitian ini dilakukan untuk mengetahui strategi manajemen apa yang paling tepat digunakan dalam meningkatkan daya saing pada Celebrity Fitness Central Park Mall. Penelitian ini menerapkan metode kualitatif, dengan melakukan wawancara serta observasi dengan meninjau secara langsung subjek penelitian. Metode analisis yang dilakukan terdiri dari tahap input yang terdiri dari Internal Factor Evaluation dan External Factor Evaluation, tahap pencocokkan yang terdiri dari Strength-Weakness-Opportunity-Threat Matrix dan Internal External Matrix, dan tahap keputusan yang terdiri dari Quantitative Strategic Planning Matrix. Setelah melakukan analisis dari data yang ada, diketahui bahwa strategi Market Penetration adalah strategi yang paling tepat diimplementasikan terhadap Celebrity Fitness Central Park dan strategi Market Development dapat digunakan sebagai strategi pendukung.

Keywords : Strategy Management, Quantitative Strategic Planning Matrix, Fitness Center

\section{Pendahuluan}

Menjalani gaya hidup sehat bukanlah lagi suatu pilihan, namun menjadi suatu keharusan. Dimulai dari mengonsumsi makanan dan minuman yang cocok untuk melakukan diet, melakukan kebiasaan baru yang dapat meningkatkan kesehatan secara bertahap, dan yang paling lazim dan efektif untuk dilakukan adalah berolahraga. Salah satu pusat kebugaran terbesar di Indonesia adalah Celebrity Fitness.

Salah satu contoh cabang Celebrity Fitness yang cukup sukses adalah Celebrity Fitness cabang Central Park Mall. Cabang tersebut melihat kinerja mereka dari tingkat banyaknya konsumen atau member di suatu cabang tertentu. Namun, dalam upaya untuk meningkatkan dan mempertahankan member-member tersebut, tidaklah mudah. Butuh banyak pertimbangan dan usaha dari berbagai aspek yang Celebrity Fitness dapat lakukan untuk mencapai target tersebut.

Tujuan dari penelitian ini adalah untuk mengkaji faktor internal dan eksternal perusahaan dalam meningkatkan strategi manajemen perusahaan dan merumuskan strategi apa yang harus diterapkan dalam meningkatkan daya saing Celebrity Fitness Central Park Mall.

\section{Tinjauan Pustaka}

Manajemen Strategi

Menurut Thomas Wheelen (2010), manajemen strategi adalah serangkaian dari pada keputusan manajerial dan kegiatan-kegiatan yang menentukan keberhasilan perusahaan dalam 
jangka panjang. Kegiatan tersebut terdiri dari perumusan atau perencanaan strategi, pelaksanaan atau implementasi dan evaluasi.

\section{External Factor Evaluation (EFE) Matrix}

Menurut David (2017), Matriks EFE (External Factor Evaluation) memungkinkan para penyusun strategi untuk meringkas dan mngevaluasi informasi ekonomi, sosial, budaya, demografis, lingkungan, politik, pemerintah, hukum, teknologi, dan kompetitif.

\section{Internal Factor Evaluation (IFE) Matrix}

Menurut David (2017), matriks IFE (Internal Factor Evaluation) merupakan strategi untuk meringkas dan mengevaluasi kekuatan dan kelemahan utama dalam area-area fungsional bisnis, dan juga menjadi landasan untuk mengidentifikasi serta mengevaluasi hubungan di antara area tersebut.

\section{Strength-Weakness-Opportunity-Threat (SWOT) Matrix}

Teori SWOT (Strengths- Weaknesses- Opportunities- Threats) menurut Wheelen dan Hunger (2010) merupakan sebuah langkah untuk dapat mengidentifikasi faktor internal dan eksternal yang berpengaruh terhadap pencapaian tujuan organisasi.

\section{Internal External (IE) Matrix}

Rangkuti (2001) menyatakan, matriks Internal Eksternal merupakan sebuah model yang dikembangkan dari model General Electric, parameter yang digunakan meliputi parameter kekuatan internal perusahaan dan pengaruh eksternal yang dihadapi perusahaan. Tujuan penggunaan model ini adalah untuk memperoleh strategi bisnis di tingkat korporasi yang lebih detail.

\section{Quantitative Strategic Planning Matrix (QSPM)}

Menurut David (2017), di luar strategi-strategi pemeringkatan untuk mendapatkan daftar prioritas, hanya ada satu teknik analisis dalam literatur yang dirancang untuk menentukan daya tarik relatif dari berbagai tindakan alternatif. Teknik tersebut adalah QSPM (Quantitive Strategic Planning Matrix), yang menyusun Tahap 3 dari kerangka analitis perumusan strategi. Teknik ini secara objektif menunjukan strategi mana yang terbaik.

\section{Metode Penelitian}

Metode penelitian pada penelitian ini lebih memfokuskan pada studi kasus, yang merupakan penelitian terperinci mengenai suatu obyek tertentu selama waktu tertentu, termasuk lingkungan dan kondisi masa lalunya dengan cukup mendalam dan menyeluruh. Menurut David (2017), terdapat 3 tahapan dalam membuat kerangka analisa perencanaan strategi, yaitu The Input Stage yang terdiri dari Internal Factor Evaluation (IFE) Matrix dan External Factor Evaluation (EFE) Matrix, The Matching Stage yang terdiri dari StrengthWeakness-Opportunity-Threat (SWOT) Matrix dan Internal External (IE) Matrix, dan The Decision Stage yang terdiri dari Quantitative Strategic Planning Matrix (QSPM).

\section{Hasil Analisis Data}

\begin{tabular}{|l|c|c|c|}
\hline \multicolumn{1}{|c|}{ Faktor-faktor Strategi Internal } & Weight & Rating & Weighted Score \\
\hline Kekuatan : & & & \\
1. Lokasi outlet atau gerai yang strategis & 0,10 & 4 & 0,40 \\
2. Memiliki promo-promo yang menarik & 0,08 & 3 & 0,24 \\
3. Memiliki kualitas fasilitas yang baik & 0,14 & 4 & 0,56 \\
4. Jam operasional + 17 jam sehari & 0,07 & 3 & 0,21 \\
5. Kapabilitas SDM yang baik & 0,22 & 4 & 0,88 \\
\hline
\end{tabular}




\begin{tabular}{|l|c|c|c|}
\hline \hline 6. Pelayanan pelanggan yang baik & 0,09 & 3 & 0,27 \\
\hline Kelemahan : & & & \\
1. Kurangnya maintenance fasilitas & 0,10 & 1 & 0,10 \\
2. Varian peralatan yang relatif homogen & 0,09 & 2 & 0,18 \\
3. Lamanya masa maintenance fasilitas & 0,11 & 1 & 0,11 \\
\hline Total & $\mathbf{1 , 0 0}$ & & $\mathbf{2 , 9 5}$ \\
\hline
\end{tabular}

Tabel 1.1 Hasil Internal Factor Evaluation (IFE) Matrix

\begin{tabular}{|l|c|c|c|}
\hline \multicolumn{1}{|c|}{ Faktor-faktor Strategi Eksternal } & Bobot & Rating & $\begin{array}{c}\text { Weighted } \\
\text { Score }\end{array}$ \\
\hline Peluang: & & & \\
1. Kesadaran masyarakat akan kesehatan yang semakin meningkat & 0,10 & 4 & 0,40 \\
2. Permintaan pasar yang semakin kompleks & & & \\
3. Pertumbuhan industri kesehatan yang meningkat & 0,10 & 4 & 0,40 \\
4. Pertumbuhan penduduk usia produktif yang pesar & 0,05 & 4 & 0,20 \\
5. Gaya hidup masyarakat yang menginginkan kemudahan & 0,16 & 3 & 0,48 \\
& 0,14 & 3 & 0,42 \\
\hline Ancaman: & 0,16 & 4 & 0,64 \\
1. Meningkatnya kompetitor di bidang pusat kebugaran & 0,15 & 4 & 0,60 \\
2. Persaingan harga & 0,03 & 2 & 0,06 \\
3. Hadirnya produk pengganti yang mudah dijangkau masyarakat & & & 0,21 \\
4. Banyaknya instruktur dan pelatih yang menawarkan jasa di luar \\
naungan perusahaan & 0,07 & 3 & 0,21 \\
5. Kondisi wilayah yang membuat masyarakat malas berpergian & & & 0,08 \\
keluar & 0,04 & 2 & $\mathbf{1 . 0 0}$ \\
\hline Total & & $\mathbf{3 , 4 9}$ \\
\hline
\end{tabular}

Tabel 1.2 Hasil External Factor Evaluation (EFE) Matrix

Dari tabel 1.1 dan tabel 1.2 dapat disimpulkan bahwa Celebrity Fitness Central Park Mall mampu memaksimalkan kekuatan yang dimiliki, meninimalkan kelemahannya, menghadapi ancaman dan memanfaatkan peluang dengan sangat baik karena jumlah total dari weighted score melebihi 2,50 .

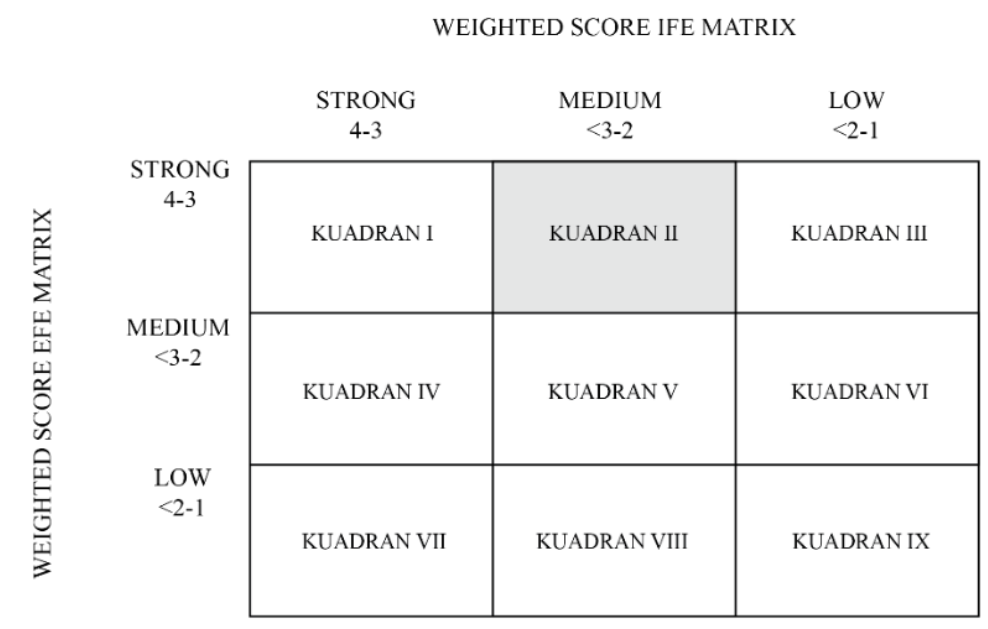

Tabel 1.3 Hasil Internal External (IE) Matrix

Matriks IE menentukan letak posisi perusahaan dalam sembilan kotak dengan tiga area strategis yang berbeda. Weighted Score dari matriks IFE adalah 2,95, sedangkan weighted score dari matriks EFE adalah 3,49. Dari hasil penyusunan kedua matriks tersebut, maka perusahaan berada pada kotak (kuadran) II dengan strategi perusahaan antara lain seperti market penetration, market development dan product development. 


\begin{tabular}{|c|c|c|}
\hline & \begin{tabular}{l}
\multicolumn{1}{c}{ Strength - S (Kekuatan) } \\
1. Lokasi outlet atau gerai yang \\
strategis \\
2. Memiliki promo-promo \\
yang menarik \\
3.Memiliki kualitas fasilitas \\
yang baik \\
4. Jam operasional + 17 jam \\
sehari \\
5. Kapabilitas SDM yang baik \\
6. Pelayanan pelanggan yang \\
baik
\end{tabular} & $\begin{array}{l}\text { Weakness - W (Kelemahan) } \\
\text { 1.Kurangnya maintenance } \\
\text { fasilitas } \\
\text { 2. Varian peralatan yang relatif } \\
\text { homogen } \\
\text { 3. Lamanya masa maintenance } \\
\text { fasilitas }\end{array}$ \\
\hline $\begin{array}{l}\text { Opportunity - O (Peluang) } \\
\text { 1. Kesadaran masyarakat akan } \\
\text { kesehatan yang semakin } \\
\text { meningkat } \\
\text { 2. Permintaan pasar yang } \\
\text { semakin kompleks } \\
\text { 3. Pertumbuhan industri } \\
\text { kesehatan yang meningkat } \\
\text { 4. Pertumbuhan penduduk usia } \\
\text { produktif yang pesat } \\
\text { 5. Gaya hidup masyarakat yang } \\
\text { menginginkan kemudahan }\end{array}$ & $\begin{array}{l}\text { Strategi SO } \\
\text { 1.Meningkatkan penjualan } \\
\text { melalui program referral } \\
\text { customer (S2, S6, O1, O4) } \\
\text { (Market Development) } \\
\text { 2. Pemberian reward terhadap } \\
\text { member (S2, S3, S5, S6, O1, } \\
\text { O3, O4, O5) (Market } \\
\text { Penetration) } \\
\text { 3. Mengembangkan aplikasi } \\
\text { CelfitTV (S3, S5, S6, O1, O2, } \\
\text { O3, O5) (Market Development } \\
\text { \& Penetration) }\end{array}$ & $\begin{array}{l}\text { Strategi WO } \\
\text { 1. Menyediakan produk dan } \\
\text { jasa yang lebih bervariatif } \\
\text { (W2, O1, O2) (Market } \\
\text { Penetration \& Development) } \\
\text { 2. Meningkatkan layanan } \\
\text { pelanggan (W1, W3, O1, O2, } \\
\text { O3) (Market Development \& } \\
\text { Penetration) } \\
\text { 3. Meningkatkan kinerja } \\
\text { karyawan (W1, W3, O1, O2, } \\
\text { O3) (Market Penetration) }\end{array}$ \\
\hline $\begin{array}{l}\text { Threats - T (Ancaman) } \\
\text { 1.Meningkatnya kompetitor di } \\
\text { bidang pusat kebugaran } \\
\text { 2. Persaingan harga } \\
\text { 3.Hadirnya produk pengganti } \\
\text { yang mudah dijangkau } \\
\text { masyarakat } \\
\text { 4. Banyaknya instruktur dan } \\
\text { pelatih yang menawarkan jasa } \\
\text { di luar naungan perusahaan } \\
\text { 5. Kondisi wilayah yang } \\
\text { membuat masyarakat malas } \\
\text { berpergian keluar }\end{array}$ & $\begin{array}{l}\text { Strategi ST } \\
\text { 1. Menghadirkan layanan } \\
\text { Personal Training one-off } \\
\text { tanpa kontrak (S2, S5, S6, T1, } \\
\text { T3, T4) (Market Penetration) } \\
\text { 2. Menggunakan website } \\
\text { sebagai sarana pendaftaran } \\
\text { member (S4, S6, T1, T5) } \\
\text { (Market Development) } \\
\text { 3. Menggunakan website } \\
\text { sebagai sarana perpanjangan } \\
\text { member (S4, S6, T1, T5) } \\
\text { (Market Penetration) }\end{array}$ & $\begin{array}{l}\text { Strategi WT } \\
\text { 1. Mempercepat proses } \\
\text { maintenance fasilitas (W3, T1, } \\
\text { T3) (Market Penetration) } \\
\text { 2. Menjaga kualitas dari } \\
\text { fasilitas yang tersedia (W1, } \\
\text { W2, W3, T1, T3, T5) (Market } \\
\text { Penetration) }\end{array}$ \\
\hline
\end{tabular}

Tabel 1.4 Hasil Strength-Weakness-Opportunity-Threat (SWOT) Matrix

Pada tabel di atas, dapat dilihat alternatif-alternatif strategi yang diperoleh dari matriks SWOT kemudian diolah untuk merumuskan strategi-strategi final yang dapat dipakai untuk meningkatkan daya saing Celebrity Fitness Central Park Mall.

\begin{tabular}{|c|c|c|c|c|c|}
\hline & & \multicolumn{2}{|c|}{ Strategi Market Penetration } & \multicolumn{2}{c|}{ Strategi Market Development } \\
\cline { 3 - 6 } $\begin{array}{c}\text { Faktor } \\
\text { Kunci }\end{array}$ & Bobot & $\begin{array}{c}\text { Attractiveness } \\
\text { Score }\end{array}$ & $\begin{array}{c}\text { Total } \\
\text { Attractiveness } \\
\text { Score }\end{array}$ & $\begin{array}{c}\text { Attractiveness } \\
\text { Score }\end{array}$ & $\begin{array}{c}\text { Total } \\
\text { Attractiveness } \\
\text { Score }\end{array}$ \\
\hline Peluang 1 & 0,10 & 4 & 0,40 & 4 & 0,40 \\
\hline Peluang 2 & 0,10 & 4 & 0,40 & 4 & 0,40 \\
\hline Peluang 3 & 0,05 & 4 & 0,20 & 4 & 0,20 \\
\hline Peluang 4 & 0,16 & 3 & 0,48 & 4 & 0,64 \\
\hline Peluang 5 & 0,14 & 4 & 0,56 & 2 & 0,28 \\
\hline
\end{tabular}




\begin{tabular}{|c|c|c|c|c|c|}
\hline \hline Ancaman 1 & 0,16 & 4 & 0,64 & 4 & 0,64 \\
\hline Ancaman 2 & 0,15 & 4 & 0,60 & 4 & 0,60 \\
\hline Ancaman 3 & 0,03 & 4 & 0,12 & 4 & 0,12 \\
\hline Ancaman 4 & 0,07 & 4 & 0,28 & 3 & 0,21 \\
\hline Ancaman 5 & 0,04 & 3 & 0,12 & 4 & 0,16 \\
\hline & $\mathbf{1 , 0 0}$ & & $\mathbf{3 , 8 0}$ & & $\mathbf{3 , 6 5}$ \\
\hline Kekuatan 1 & 0,10 & 3 & 0,30 & 4 & 0,40 \\
\hline Kekuatan 2 & 0,08 & 3 & 0,24 & 4 & 0,32 \\
\hline Kekuatan 3 & 0,14 & 4 & 0,56 & 4 & 0,56 \\
\hline Kekuatan 4 & 0,07 & 4 & 0,28 & 4 & 0,28 \\
\hline Kekuatan 5 & 0,22 & 4 & 0,88 & 4 & 0,88 \\
\hline Kekuatan 6 & 0,09 & 4 & 0,36 & 4 & 0,36 \\
\hline Kelemahan 1 & 0,10 & 4 & 0,40 & 2 & 0,20 \\
\hline Kelemahan 2 & 0,09 & 3 & 0,27 & 3 & 0,27 \\
\hline Kelemahan 3 & 0,11 & 2 & 0,22 & 3 & 0,33 \\
\hline & $\mathbf{1 , 0 0}$ & & $\mathbf{3 , 5 1}$ & & $\mathbf{3 , 6 0}$ \\
\hline Total & & & $\mathbf{7 , 3 1}$ & & $\mathbf{7 , 2 5}$ \\
\hline
\end{tabular}

Tabel 1.5 Hasil Quantitative Strategic Planning Matrix (QSPM)

Dari tabel di atas, dapat dilihat bahwa Total Attractiveness Score dari Strategi Market Penetration mempunyai nilai total yang lebih tinggi dari Strategi Market Development. Maka dapat disimpulkan bahwa strategi yang paling tepat untuk meningkatkan daya saing Celebrity Fitness Central Park Mall adalah Strategi Market Penetration dan strategi pendukungnya adalah strategi Market Development.

\section{Kesimpulan dan Saran}

Dari hasil penelitian pada bab pembahasan, dapat disimpulkan bahwa faktor internal dan eksternal (kekuatan, kelemahan, peluang, dan ancaman) dari dan terhadap Celebrity Fitness Central Park Mall dapat dilihat dari hasil analisis data dari matriks IFE dan matriks EFE, dan atau matriks SWOT. Saran untuk Celebrity Fitness Central Park Mall adalah menggunakan strategi Market Penetration sebagai strategi utama dan strategi Market Development sebagai strategi pendukung.

\section{Daftar Pustaka}

David, M.E., David, Forest. R., \& David, Fred. R., "The quantitative strategic planning matrix (QSPM) applied to a retail computer centre," The Coastal Business Journal, pp. 42-52, 2009.

David, Forest. R. \& David, Fred. R., (2017). Strategic Management A Competitive Advantage Approach, Concepts and Cases. $16^{\text {th }}$ Edn. Pearson.

Rangkuti, Freddy. (2001). Analisis SWOT Teknik Membelah Kasus Bisnis. PT. Gramedia Pustaka Utama: Jakarta.

Wheelen, Thomas L, and J D. Hunger.2010. Strategic Management and Business Policy: Achieving Sustainability. Prentice Hall: Upper Saddle River, N.J 